Document downloaded from:

http://hdl.handle.net/10251/180762

This paper must be cited as:

Correia, D.; Costa, C.; Lizundia, E.; Sabater I Serra, R.; Gómez-Tejedor, J.; Teruel Biosca, L.; Meseguer Dueñas, JM.... (2019). Influence of Cation and Anion Type on the Formation of the Electroactive beta-Phase and Thermal and Dynamic Mechanical Properties of Poly(vinylidene fluoride)/Ionic Liquids Blends. The Journal of Physical Chemistry C. 123(45):27917-27926. https://doi.org/10.1021/acs.jpcc.9b07986

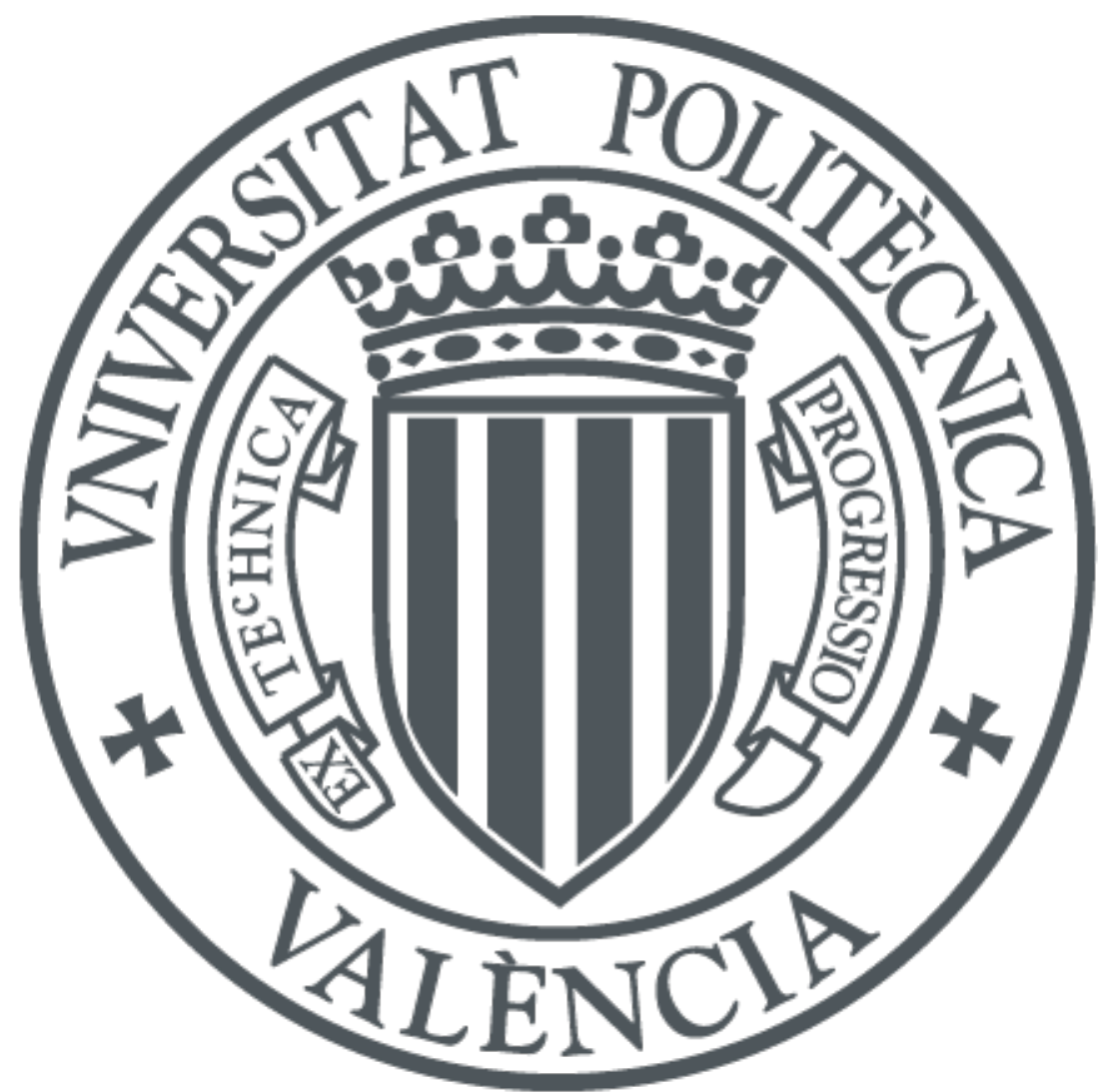

The final publication is available at

https://doi.org/10.1021/acs.jpcc.9b07986

Copyright American Chemical Society

Additional Information 


\title{
Influence of Cation and Anion Type on the Formation of the Electroactive $\beta$-Phase and Thermal and Dynamic Mechanical Properties of Poly(vinylidene fluoride)/Ionic Liquids Blends
}

\author{
Daniela M. Correia ${ }^{1,2}$, Carlos M. Costa ${ }^{2, *}$, Erlantz Lizundia ${ }^{3,4}$, Roser Sabater i Serra ${ }^{5,6}$,
} José A. Gomez-Tejedor ${ }^{5,6}$, Laura Teruel Biosca ${ }^{5}$, José M. Meseguer-Dueñas ${ }^{5,6}$, José L. Gomez Ribelles ${ }^{5,6}$, and Senentxu Lanceros-Mendez' ${ }^{4,7}$

${ }^{1}$ Department of Chemistry and CQ-VR, University of Trás-os-Montes e Alto Douro, 5000-801Vila Real, Portugal

${ }^{2}$ Centro de Física, Universidade do Minho, 4710-057 Braga, Portugal

${ }^{3}$ Department of Graphic Design and Engineering Projects, Bilbao Faculty of Engineering, University of the Basque Country (UPV/EHU), Bilbao 48013, Spain

${ }^{4}$ BCMaterials, Basque Center for Materials, Applications and Nanostructures, UPV/EHU Science Park, 48940 Leioa, Spain

${ }^{5}$ Centre for Biomaterials and Tissue Engineering, CBIT, Universitat Politècnica de València, 46022 Valencia, Spain

${ }^{6}$ Biomedical Research Networking Center on Bioengineering, Biomaterials and Nanomedicine (CIBER-BBN), Valencia, Spain

${ }^{7}$ IKERBASQUE, Basque Foundation for Science, 48013, Bilbao, Spain

\begin{abstract}
Films based on poly(vinylidene fluoride) (PVDF) blended with ionic liquids (ILs) comprising different cations and anions were developed to investigate the IL influence on the resulting PVDF crystalline phase. Blends with $25 \mathrm{wt} \%$ IL content were produced by solvent casting followed by solvent evaporation at $210^{\circ} \mathrm{C}$ in an air oven. Five different ILs containing the same cation 1-ethyl-3-methylimidazolium [Emim] and five ILs containing the same anion bis(trifluoromethylsulfonyl)imide [TFSI] were selected. The formation of the different phases and the resulting thermal and dynamic mechanical properties were studied by Fourier transform infrared spectroscopy, differential scanning calorimetry, and dynamic mechanical analysis. The incorporation of [Emim]-based ILs successfully directs the PVDF crystallization from the nonpolar $\alpha$-phase toward the electroactive and highly polar $\beta$-phase. On the contrary, blends containing [TFSI] as a
\end{abstract}


common anion yield a mixture of $\alpha$ and $\beta$ phases. Overall, the induced $\beta$-phase ranges between 14 and 95\% depending on the incorporated IL type. Interestingly, 1-ethyl-3methylimidazolium chloride $[\mathrm{Emim}][\mathrm{Cl}]$ is the most effective IL among the studied ones to significantly enhance the $\beta$-phase content, showing also a marked nucleating effect. The results suggest that ions favorably interact with PVDF chains and are located occupying the amorphous interlamellar PVDF regions. Furthermore, the studied ILs act as plasticizers, yielding lower glass-transition temperatures of the amorphous phase and decreasing mechanical storage modulus at room temperature.

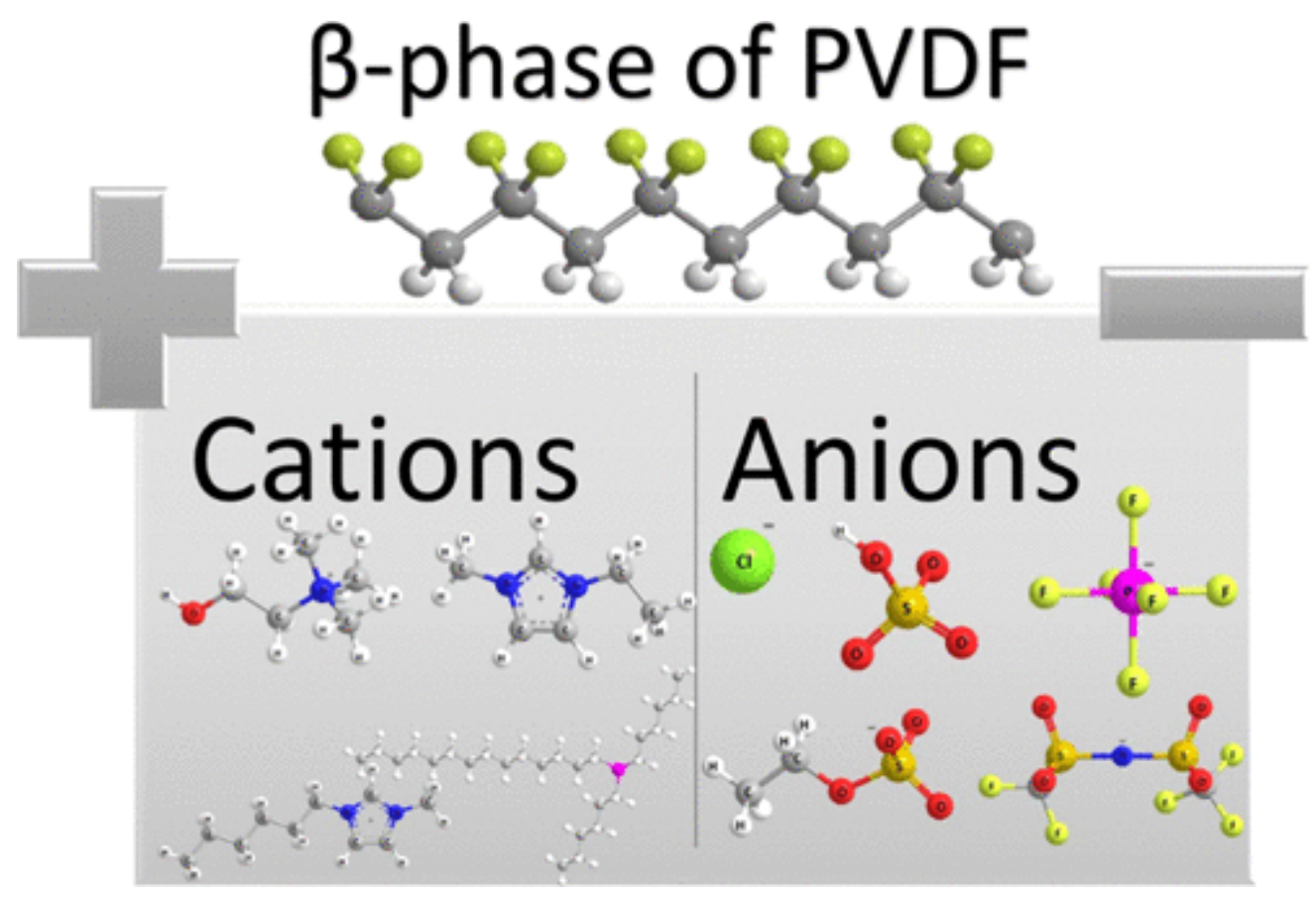

Keywords: PVDF; ionic liquids; anion; cation; crystallization. 


\section{Introduction}

Poly(vinylidene fluoride) (PVDF) is a semicrystalline polymer showing very interesting multifunctional properties for sensor and actuator applications, among others. $[1,2]$. The most common polymorph is the $\alpha$-phase, where CF2 groups are established in trans-gauche-trans conformations, which result in a nonpolar chain configuration as $\mathrm{C}-$ $\mathrm{F}$ bonds are arranged in an alternating fashion along the chain. From the other possible four polymorphs $(\beta, \gamma, \delta$, and $\varepsilon)$, the $\beta$-phase is the most technologically relevant for applications, where $\mathrm{C}-\mathrm{F}$ bonds are normal to the backbone chain and the obtained alltrans conformation leads to a large piezoelectric and ferroelectric response [2]. A wide range of applications such as capacitors, battery separator, or sensors have been proposed so far for $\beta$-PVDF [3-5]. The $\alpha$ phase is the most common form of PVDF as it is obtained during crystallization from the melt. As a result, many works have been focused on the development of $\beta$-phase containing PVDF. The techniques reported so far to obtain the $\beta$-phase PVDF include, but are not limited to, filler addition [6], blending [7], poling [8], stretching [9], or by nanoconfinement [10].

Although such techniques have proven efficient toward the development of electroactive PVDF, these approaches suffer from challenges associated with homogeneous filler dispersion (composite preparation), phase separation (polymer blending), or expensive and tedious processes (poling, stretching, and nanoconfinement), which limit their processability at industrial level. An efficient and straightforward approach to circumvent the above-mentioned issues may be the incorporation of organic compounds in a PVDF matrix by simple mixing processes. In that framework, roomtemperature ionic liquids (ILs) emerge as a perfect choice as they can be easily processed at room temperature by simply incorporating selected ILs into dissolved PVDF and have been proven to be highly compatible with many polymer matrices [11-13]. ILs are salts whose melting point is below $100{ }^{\circ} \mathrm{C}$ and are composed of a small anion and an asymmetric heterocyclic cation [14]. Moreover, ILs are generally considered as environmentally benign [15], present a negligible vapor pressure, and their high thermal stability and ionic conductivity may serve to upgrade the multifunctional properties of PVDF [16]. The influence of the incorporation of ILs into the PVDF polymer matrix, such as 1-hexadecyl-3-methylimidazolium bromide [C16mim][Br] [17], or butyl methylimidazolium hexafluorophosphate [Bmim][PF6] [18], on the physical and chemical properties of the PVDF has been studied. It has been reported that the 
incorporation of ILs into the PVDF polymer matrix induces an extended conformation of PVDF into its polar $\beta$-phase and that PVDF/IL blends show excellent mechanical characteristics, with significantly increased ductility, good optical transmittance, and higher electrical conductivity [18]. However, to the best of our knowledge, no studies have systematically reported on the influence of the ILs with different functional groups on the PVDF crystallization process toward the formation of the $\beta$-phase. In this sense, strong dipolar interactions are expected between the heterocyclic cation of ILs and the CF2 moiety of PVDF. Similarly, the nature of the anion could also influence the resulting interactions between the IL and the polymer. PVDF/IL blends in the form of films with IL with different cation chain sizes have been evaluated showing that the characteristics of the IL strongly influence the physicochemical characteristics of the composites, including the increase of the alternating current conductivity [19].

In a previous work, the mixture of PVDF and ionic liquid 1-ethyl-3methylimidazolium [Emim] bis(trifluoromethylsulfonyl)imide [TFSI] was evaluated, analyzing the dependence of the melting temperatures and crystallization on IL concentration within the polymer matrix. It was observed that the presence of IL induced the formation of the $\beta$ phase of PVDF [20]. In the present work, we have extended the study to a wide series of ILs with different anions and cations to analyze the influence of the interaction of the anion and cation with the polymer chains in the crystallization of the PVDF. Accordingly, in this work, blends of PVDF with 10 different ILs were prepared to study the effect of the anion (by keeping the cation unchanged) and cation (by keeping the anion unchanged) on the conformation and crystalline structure of PVDF. The associated thermal transitions and dynamic mechanical properties are also discussed.

\section{Experimental section}

\subsection{Materials}

PVDF (Solef 6020, $M_{\mathrm{w}}=700000 \mathrm{~g} \mathrm{~mol}^{-1}$ ) was purchased from Solvay, and $N, N$ dimethylformamide (DMF) (99.5\%) was obtained from Merck. The ILs used in this work, comprising different cations and anions, were obtained from IoLiTec and are indicated in Table 1. The effect of the anion was evaluated using the following ILs: 1-ethyl-3methylimidazolium hexafluorophosphate $[\mathrm{Emim}]\left[\mathrm{PF}_{6}\right]$, 1-ethyl-3-methylimidazolium chloride $\left[\right.$ Emim] $[\mathrm{Cl}]$, 1-ethyl-3- methylimidazolium hydrogen sulfate [Emim] $\left[\mathrm{HSO}_{4}\right], 1$ - 
ethyl-3-methylimidazolium ethylsulfate [Emim $]\left[\mathrm{C}_{2} \mathrm{SO}_{4}\right]$, and 1-ethyl-3methylimidazolium bis(trifluoromethylsulfonyl)imide [Emim][TFSI]. 1-Hexyl-3methylimidazolium bis(trifluormethylsulfonyl)imide [Hmim][TFSI], 1-octyl-3methylimidazolium bis(trifluoromethanesulfonyl)imide $\quad$ [Dmim][TFSI], $N, N, N$ trimethyl-N-(2-hydroxyethyl)ammonium bis(trifluoromethylsulfonyl)imide [N1112OH][TFSI], trihexyl(tetradecyl)phosphonium bis(trifluoromethylsulfonyl)imide [P66614][TFSI], and 1-butyl-1-methylpyrrolidinium bis(trifluoromethanesulfonyl)imide [C4C1Pyrr][TFSI] were used to study the effect of the cation on the properties of the blends. The selection of the different cations and anions is based on the different structural and dimensional characteristics, as presented in Table 1, modulating therefore the interactions with the polymer chain.

Table 1 - Structure and Melting Temperature of the ILs Used for the Preparation of the IL-PVDF Blends.

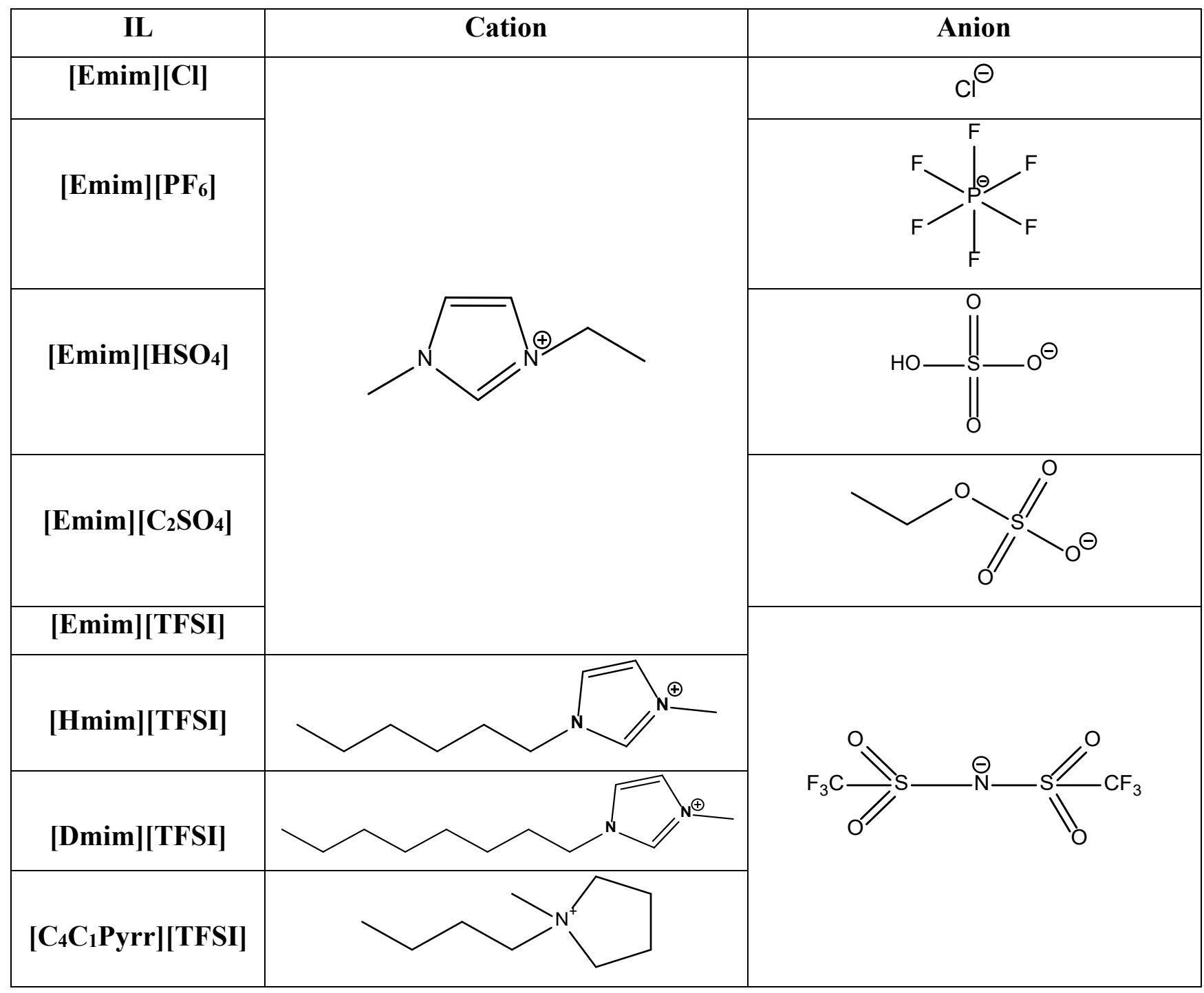




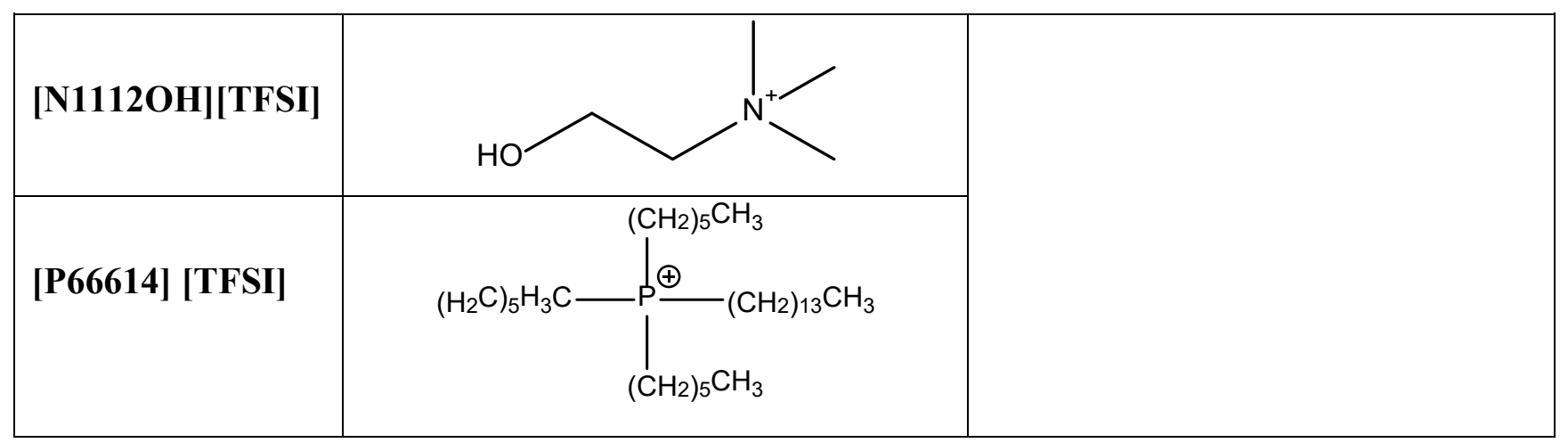

\subsection{Sample preparation}

PVDF was dissolved in DMF in a proportion of $15 / 85 \mathrm{wt} \%$ under magnetic stirring at room temperature. After complete polymer dissolution, the selected ILs ( $25 \mathrm{wt} \%$ ) were added to the solution. The IL content of $25 \mathrm{wt} \%$ was selected as it has been demonstrated that this amount is high enough to allow substantial nucleation of the electroactive phase by different ILs, allowing a suitable comparison among them [21,22]. PVDF/IL films with a thickness of approximately $50 \mu \mathrm{m}$ were obtained after spreading the solution at room temperature on a glass substrate followed by solvent evaporation at $210{ }^{\circ} \mathrm{C}$ (above melting temperature of the polymer for complete and rapid solvent evaporation) in an air oven (P-Selecta), following the general procedure described in ref [23].

\subsection{Characterization techniques}

Fourier transform infrared (FTIR) measurements were carried out with a Jasco 4100 spectrometer in the attenuated total reflection (ATR) mode from 4000 to $400 \mathrm{~cm}^{-1}$. FTIR spectra were collected after 64 scans with a resolution of $4 \mathrm{~cm}^{-1}$. Differential scanning calorimetry (DSC) was carried out with a DSC Mettler Toledo 823e for low-temperature measurements conducted in the region of glass transition and a DSC 8000 of PerkinElmer for scans in the crystallization and melting region, in both cases under flowing nitrogen $\left(\mathrm{N}_{2}\right)$ atmosphere. The mass of the sample was between 5 and $10 \mathrm{mg}$. Dynamic mechanical analysis (DMA) was carried out in a PerkinElmer DMA 8000 apparatus in tensile mode. The storage modulus and loss tangent were measured as a function of temperature at a frequency of $1 \mathrm{~Hz}$ from -100 to $125^{\circ} \mathrm{C}$ at a heating rate of $2{ }^{\circ} \mathrm{C} \mathrm{min}{ }^{-1}$. The dimension of each sample was around $10 \times 4 \times 0.050 \mathrm{~mm}^{3}$. For each sample, the FTIR spectra and DSC and DMA curves were measured in triplicate. 


\section{Results and discussion}

\subsection{FTIR characterization}

Both blend constituents, ILs and PVDF, have the ability to crystallize, with the melting temperature of the ILs below the melting temperature of PVDF. At temperatures above the melting temperature of PVDF, a homogeneous mixture of IL and PVDF liquid chains is expected. Thus, on cooling, nucleation and growth of PVDF crystals take place in an environment in which chain segments interact with IL ions and, on the other hand, an environment in which the conformational mobility of PVDF macromolecules is higher than in pure PVDF, which is attributed to the interaction of the ILs with the PVDF polymer chain (cation-polymer and anion-polymer interactions) [24]. Both these factors are expected to influence the crystallinity and the crystal phase of the polymer. Therefore, here we attempt to analyze the effect of different ILs on the crystalline structure of PVDF blends.

To obtain a homogeneous mixture of PVDF and IL, the samples were obtained after dissolving PVDF and the required IL in DMF, followed by a solvent evaporation process at high temperatures $\left(210^{\circ} \mathrm{C}\right)[23]$ to promote the crystallization process through cooling from the molten blend.

The effect of the different ILs on the PVDF chemical properties was evaluated by FTIR-ATR analysis through the identification and quantification of the different crystal phases of PVDF. Figure 1a displays the FTIR spectra of both PVDF film, [Emim] $\left[\mathrm{C}_{2} \mathrm{SO}_{4}\right]$ IL, and the corresponding blend. Neat PVDF displays sharp bands at 615, 763, 796, and $976 \mathrm{~cm}^{-1}$, which correspond to the $\alpha$-phase. [25]. It is interesting to note that no conformational changes are obtained upon the processing of PVDF powder into films by solvent casting followed by drying at $210^{\circ} \mathrm{C}$ (as supported by the FTIR spectra in Figure $\mathrm{S} 1$, where both samples present virtually identical spectra). The PVDF/[Emim] $\left[\mathrm{C}_{2} \mathrm{SO}_{4}\right]$ blend presents a weak absorption band at $1275 \mathrm{~cm}^{-1}$ and a stronger one at $840 \mathrm{~cm}^{-1}$, both ascribed to the $\beta$-phase [25]. The absorption bands at 1071, 1176, and $1402 \mathrm{~cm}^{-1}$ are also assigned to $\beta$ PVDF $[24,26]$. Remarkably, with the IL incorporation, the intensity of the absorption bands characteristic of the $\alpha$-phase significantly decreases. The absence of a shoulder absorption band at $833 \mathrm{~cm}^{-1}$ and also the absence of peaks at 1234 and $811 \mathrm{~cm}^{-}$ ${ }^{1}$, characteristic of the $\gamma$ phase, indicate the $\mathrm{PVDF} /[\mathrm{Emim}]\left[\mathrm{C}_{2} \mathrm{SO}_{4}\right]$ blend crystallization into the polymorph $\beta$ phase $[27,28]$. This is in contrast to the previously reported works where a transformation from $\alpha$ to a mixture of $\beta$ and $\gamma$ crystal phases has been reported 
by mixing PVDF with 1-hexadecyl-3-methylimidazolium bromide $\left[\mathrm{C}_{16} \mathrm{mim}\right][\mathrm{Br}]$ [17], or 1-butyl-3-methylimidazolium hexafluorophosphate $\left.\left[\mathrm{Bmim}_{[}\right] \mathrm{PF}_{6}\right]$ [18]. In marked contrast to the directing effect of $[\mathrm{Emim}]\left[\mathrm{C}_{2} \mathrm{SO}_{4}\right]$, Figure $1 \mathrm{~b}$ shows that the incorporation of $[\mathrm{Emim}]\left[\mathrm{PF}_{6}\right]$ into PVDF does not promote modifications in the crystal phase of PVDF films as the obtained spectra are a mere superposition of the $\alpha$-containing PVDF and the IL due to the small size of the anion. This fact reveals the relevance of the selection of ILs with an appropriate anion-cation pair.
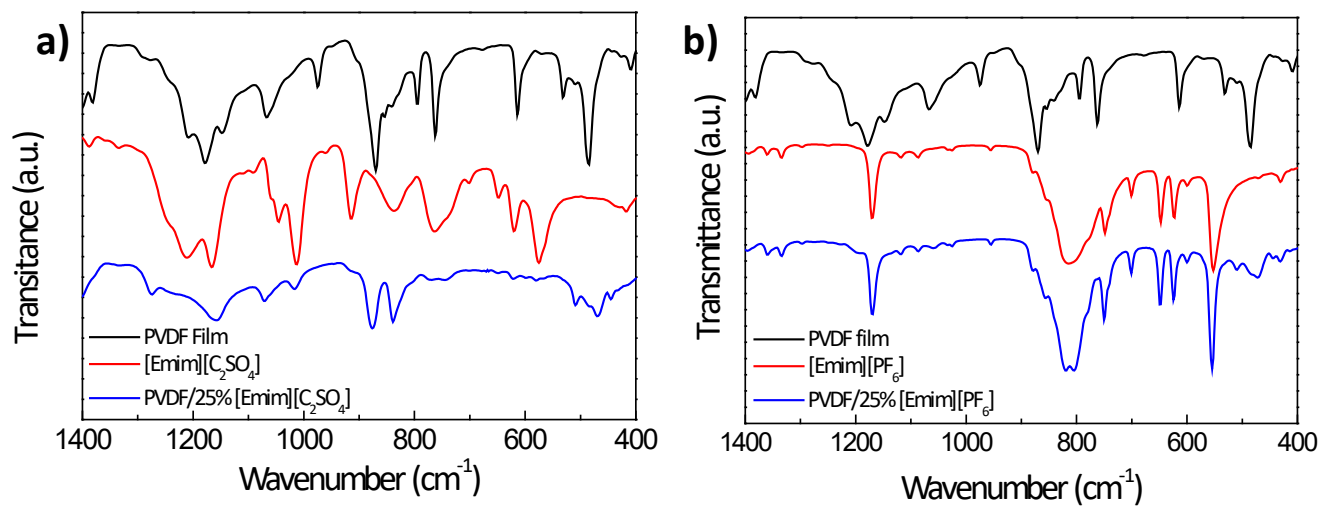

Fig. 1. a) FTIR spectra of neat PVDF film, neat $[$ Emim $]\left[\mathrm{C}_{2} \mathrm{SO}_{4}\right] \mathrm{IL}$, and their blend; b) FTIR spectra of neat PVDF film, neat $[\mathrm{Emim}]\left[\mathrm{PF}_{6}\right] \mathrm{IL}$, and their blend.

To search for further suitable ILs as directing agents toward the $\beta$ crystal phase, PVDF has been blended with a series of ILs having [Emim] as a common cation. Figure 2 displays the obtained results, where the most relevant PVDF fingerprint regions have been enlarged for the sake of comprehension. First, Figure $2 \mathrm{a}$ is focused on the 900-700 $\mathrm{cm}^{-1}$ region, where the bands at 763,840 , and $870 \mathrm{~cm}^{-1}$ are assigned to the $\alpha$-phase, $\beta$ phase, and amorphous PVDF, respectively. As an overall trend, all of the blends showed a decreased intensity (or even vanishing) of the $763 \mathrm{~cm}^{-1}$ absorption band together with an increase of the $840 \mathrm{~cm}^{-1}$ band, suggesting that the presence of the $\alpha$-phase is markedly reduced upon the introduction of such ILs. Moreover, it is also observed that the amorphous $870 \mathrm{~cm}^{-1}$ band of $\mathrm{CF}_{2}-\mathrm{CH}_{2}$ bending vibration tends to increase, which is indicative of the presence of larger amorphous region within the blend. This may be due to the fact that, apart from the directing effect of ILs toward the $\beta$-phase, their incorporation also brings a plasticizing effect (absorption of ions that migrate between the macromolecular chains, thus allowing the plastic part to lose stiffness) [29], which limits the organization of PVDF macromolecules into crystalline regions $[12,13]$. Interestingly, it should be noted that the amorphous PVDF band becomes wider and is 
shifted to a higher-energy region by $4-6 \mathrm{~cm}^{-1}$, indicating that $>\mathrm{CF}_{2}$ groups effectively interact with the IL [30]. This interaction denotes the good miscibility between PVDF and ILs, where IL may be found occupying amorphous interlamellar regions. The results in Figure $2 \mathrm{~b}$ agree with the directing effect of ILs as an increase of the $510 \mathrm{~cm}^{-1}$ band (corresponding to $\beta$-phase) at the expense of the $\alpha$-phase $485 \mathrm{~cm}^{-1}$ band is also observed. Finally, Figure $2 \mathrm{c}$ demonstrates that the PVDF/[Emim][TFSI] sample shows an absorption band around $1230 \mathrm{~cm}^{-1}$, indicative of the presence of $\gamma$-PVDF [28]. For all of the other samples, no trace of $\gamma$-PVDF is observed.
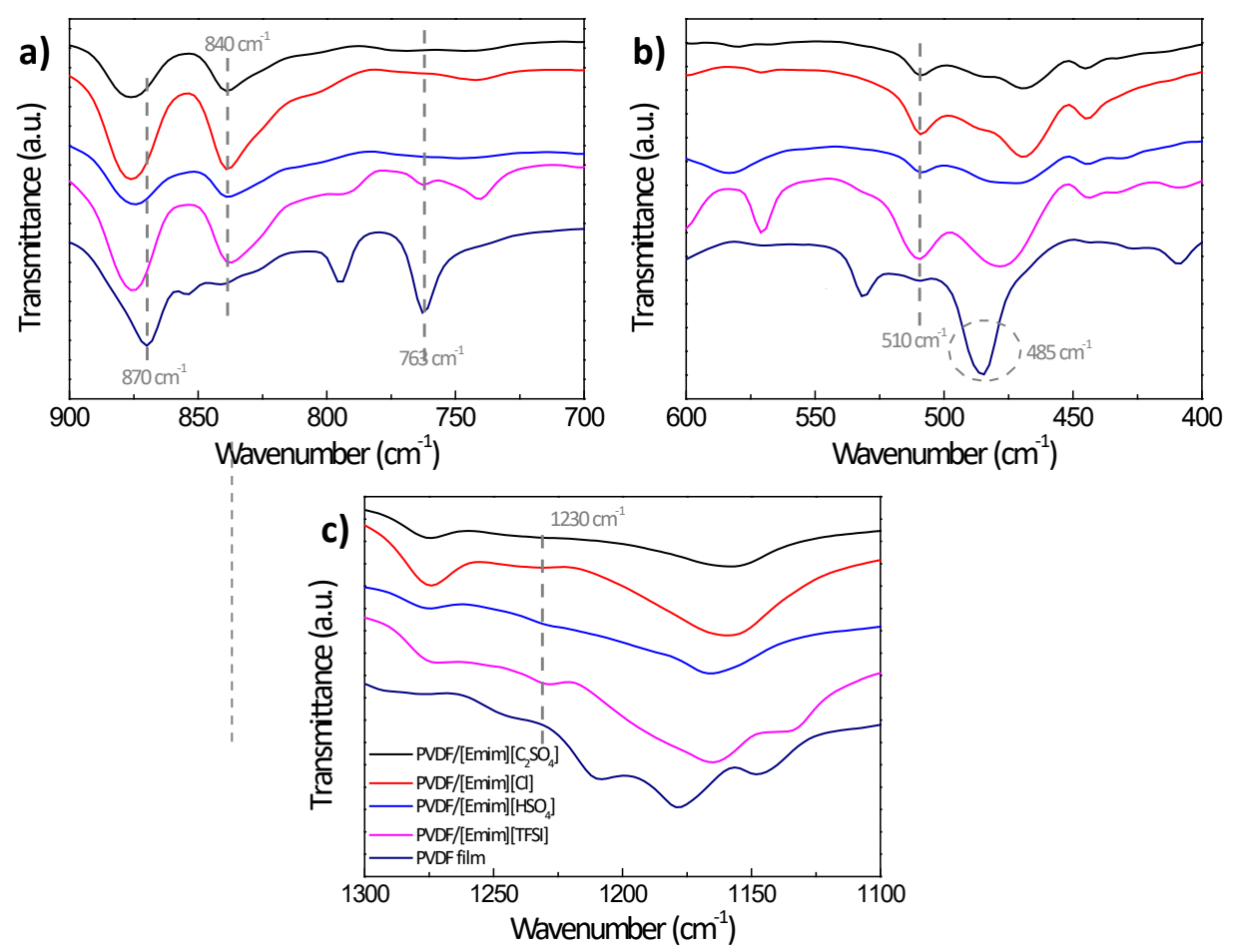

Fig. 2. FTIR spectra of PVDF/IL blends having [Emim] as a common cation in the: a) $900-700 \mathrm{~cm}^{-1}$; b) $600-400 \mathrm{~cm}^{-1}$ and c) $1300-1100 \mathrm{~cm}^{-1}$ regions.

Furthermore, it has been observed that ILs having [Emim] as a common cation have a similar effect on the crystalline phase of PVDF, independently of the anion.

Blends having an IL with a common anion have also been obtained to investigate the effect of the cation on the resulting crystalline phase. Accordingly, Figure 3 shows the FTIR spectra corresponding to the PVDF/IL blends with [TFSI] as a common anion. Therefore, those results allow to understand the effect of different cations on the crystalline phase of PVDF. Both PVDF/[Dmim][TFSI] and PVDF/[N1112OH][TFSI] blends present the $\alpha$-phase as indicated by the bands located at 763 and $485 \mathrm{~cm}^{-1}$, while 
the $840 \mathrm{~cm}^{-1}$ band indicative of the $\beta$-phase is achieved for all of the blends (despite the notable intensity differences). Similarly, blends show the $\beta$-phase absorption band at 510 $\mathrm{cm}^{-1}$ (corresponding to $\beta$-phase) together with a displacement toward higher-energy region of the $870 \mathrm{~cm}^{-1}$ band, suggesting that ILs interact with the PVDF chains. Interestingly, the blends showing $\alpha$-phase (PVDF/[Dmim][TFSI] and $\mathrm{PVDF} /[\mathrm{N} 1112 \mathrm{OH}][\mathrm{TFSI}])$ do not present a notable shift on the amorphous $870 \mathrm{~cm}^{-1}$ band and also the intensity of the $840 \mathrm{~cm}^{-1}$ band ( $\beta$-phase) is very low. Therefore, contrarily to [Emim]-containing ILs, the cationic ions in [C4C1Pyrr] and [P66614] are able to interact with the $>\mathrm{CF}_{2}$ moieties in PVDF to locate $>\mathrm{CF}_{2}$ along one side of the main chain, similarly to previously obtained PVDF samples blended with imidazolium-ion-based ionic liquids [18].

Overall, while most of the blends having [Emim] as a common cation yield the electroactive $\beta$-PVDF phase, blends having [TFSI] as a common anion yield a mixture of $\alpha, \beta$, and $\gamma$ phases. In any case, it is interesting to note that most samples with different IL types result in the crystallization of the polymer just in the electroactive and highly polar $\beta$ phase, which is in contrast to previously reported works where a mixture of both $\beta$ and $\gamma$ phases was obtained $[17,18,30]$.
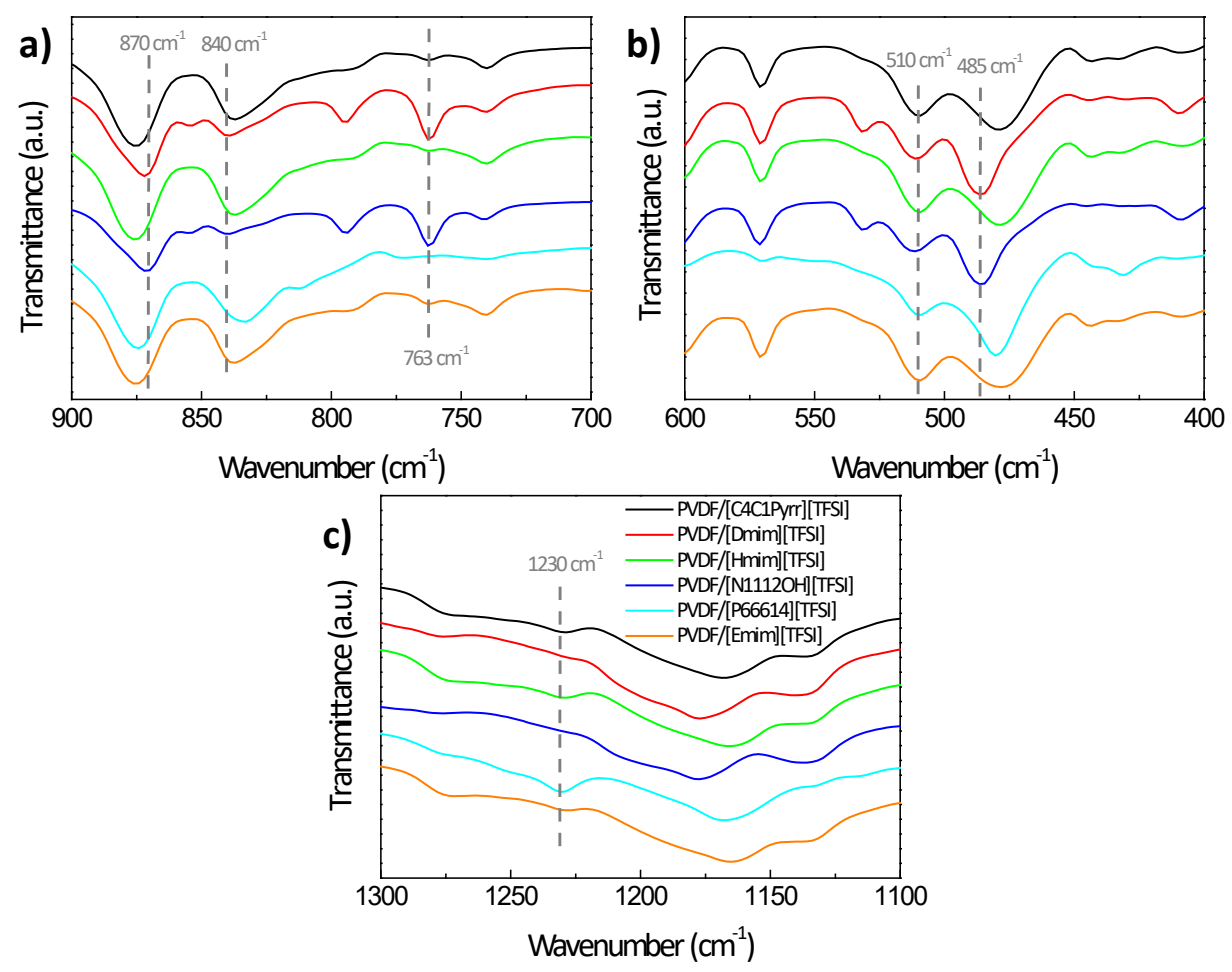

Fig. 3. FTIR spectra of PVDF/IL blends having [TFSI] as a common anion in the: a) 900$700 \mathrm{~cm}^{-1}$; b) $600-400 \mathrm{~cm}^{-1}$ and c) $1300-1100 \mathrm{~cm}^{-1}$ regions. 
It is observed that the chain structure (i.e., the anion and cation type) affects the ability of the ILs to act as directing agents for PVDF phase crystallization, highlighting the relevance of properly selecting the anion to be able to achieve the electroactive $\beta$-phase. The quantification of the $\beta$-phase could shed light on the efficiency of different ILs to give the all-trans chain conformation of PVDF as a result of the electrostatic PVDF-IL interactions through ion-dipole interactions [31]. When no coexistence of the $\beta$ and $\gamma$ crystal phases exists, the extent of the polar $\beta$ crystalline phase $(F(\beta))$ can be computed as assuming that IR absorption follows the Lambert-Beer law [32]:

$$
F(\beta)=\frac{A_{\beta}}{1.26 \cdot A_{\alpha}+A_{\beta}}
$$

where $A_{\alpha}$ and $A_{\beta}$ are the absorbances at 763 and $840 \mathrm{~cm}^{-1}$, respectively. The obtained results are reported in Table 2. It is observed that depending on the IL, $F(\beta)$ could reach up to a maximum value of $95 \%$ for the $\mathrm{PVDF} /[\mathrm{Emim}][\mathrm{Cl}]$ blend, indicating that such $\mathrm{IL}$ plays the most effective role (among the studied ILs) as directing agent for the nucleation of the electroactive $\beta$-phase during the solvent evaporation process. This may be due to the presence of a large electrostatic interaction between the negatively charged chlorine anion $\left(\mathrm{Cl}^{-}\right)$and the positively charged PVDF's dipolar moment, boosting the development of the $\beta$-phase more effectively [33]. These results prove that by selecting the proper IL, an efficient way to obtain large $\beta$-phase fractions could be achieved through this method as other approaches such as uniaxial stretching render materials with an $\alpha$ phase content that can be higher than $20 \%$ (depending on the applied stretching ratio and temperature) $[2,34]$.

Table 2. $\beta$ Crystalline PVDF Phase Obtained Depending on the IL Used for an IL Content of $25 \mathrm{wt} \%$.

\begin{tabular}{|c|c|c|c|c|c|c|}
\hline Sample & Neat PVDF & {$[\mathrm{Emim}]\left[\mathrm{C}_{2} \mathrm{SO}_{4}\right]$} & {$[$ Emim $][\mathrm{Cl}]$} & {$\left[\right.$ Emim] $\left[\mathrm{HSO}_{4}\right]$} & [Emim][TFSI] & {$[$ Emim $]\left[\mathrm{PF}_{6}\right]$} \\
\hline$F(\beta)$ & $33 \%$ & $80 \%$ & $95 \%$ & $82 \%$ & $83 \%$ & $0 \%$ \\
\hline Sample & [C4C1Pyrr][TFSI] & [Dmim][TFSI] & [Hmim][TFSI] & [N1112OH][TFSI] & [P66614][TFSI] & [Emim][TFSI] \\
\hline$F(\beta)$ & $85 \%$ & $43 \%$ & $86 \%$ & $36 \%$ & $87 \%$ & $83 \%$ \\
\hline
\end{tabular}




\subsection{DSC results}

The effect of ILs on the crystallinity of PVDF was also evaluated by DSC measurements. Accordingly, DSC cooling scans of melted PVDF/IL blends having different anions and cations are depicted in Figure 4a,b, respectively. The achieved bellshaped endothermic peak upon cooling from the melt arises from the arrangement of PVDF chains into well-ordered regions. The peak crystallization temperatures $\left(T_{\mathrm{c}}\right)$ for all of the samples together with their crystallization enthalpy $\left(\Delta H_{\mathrm{c}}\right)$ are listed in Table 3 . It is observed that upon the addition of ILs, the $T_{\mathrm{c}}$ of PVDF decreases from $134{ }^{\circ} \mathrm{C}$ to a minimum value of $113{ }^{\circ} \mathrm{C}$ for the $\mathrm{PVDF} /[\mathrm{Emim}]\left[\mathrm{PF}_{6}\right]$ as a result of the incorporation of the ILs $[18,35]$.
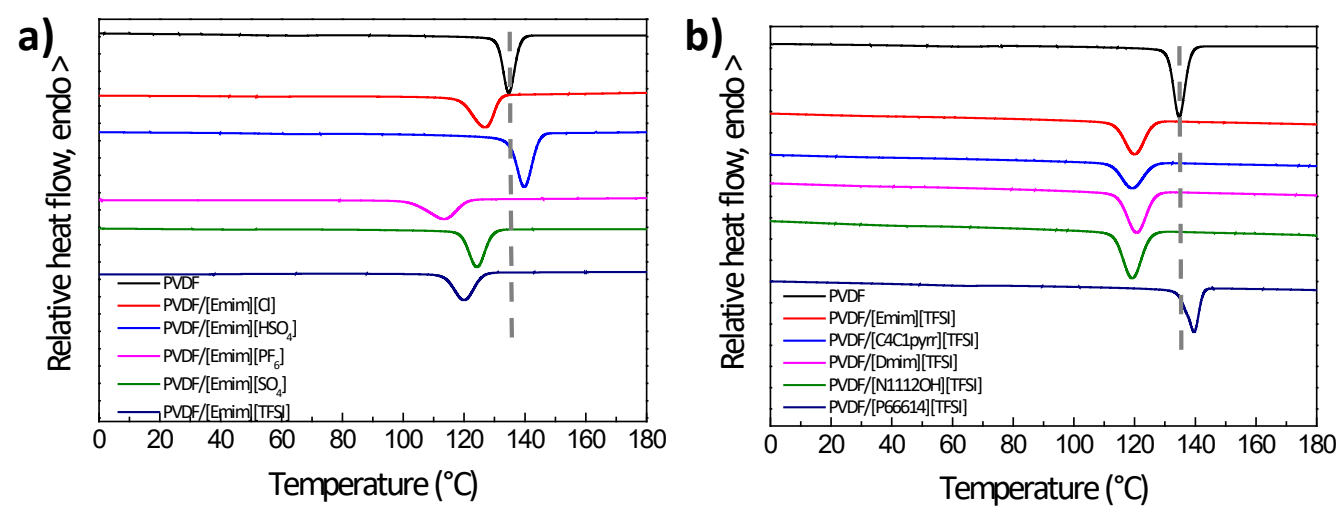

Fig. 4. DSC cooling scans of PVDF/IL blends having different a) anions and b) cations. Normalized heat flow (heat flow divided by the sample mass and the cooling rate) is represented.

Table 3. Crystallization Temperature $\left(T_{\mathrm{c}}\right)$ and Enthalpy $\left(\Delta H_{\mathrm{c}}\right)$ upon Cooling from the Melt and Melting Temperature $\left(T_{\mathrm{m}}\right)$ for the Different PVDF/IL Blends (The effect of the anion is shown on rows 2 to 6 , while rows 6 to 10 displays the effect of the cation).

\begin{tabular}{|c|c|c|c|c|}
\hline Arrow & Blend & $\boldsymbol{T}_{\boldsymbol{c}} \pm \mathbf{1}\left({ }^{\circ} \mathbf{C}\right)$ & $\boldsymbol{\Delta H}_{\boldsymbol{c}} \pm \mathbf{2 \%}\left(\mathrm{J} \cdot \mathrm{g}^{-1}\right)$ & $\boldsymbol{T}_{\boldsymbol{m}} \pm \mathbf{1}\left({ }^{\circ} \mathbf{C}\right)$ \\
\hline $\mathbf{1}$ & $\mathbf{P V D F}$ & 134 & 47 & 169 \\
\hline $\mathbf{2}$ & $\mathbf{P V D F} /[\mathrm{Emim}][\mathbf{C l}]$ & 127 & 63 & 165 \\
\hline $\mathbf{3}$ & $\mathbf{P V D F} /[\mathbf{E m i m}]\left[\mathrm{HSO}_{4}\right]$ & 139 & 86 & 172 \\
\hline $\mathbf{4}$ & $\mathbf{P V D F} /[\mathbf{E m i m}]\left[\mathbf{P F}_{\mathbf{6}}\right]$ & 113 & 48 & 158 \\
\hline $\mathbf{5}$ & $\mathbf{P V D F} /[\mathbf{E m i m}]\left[\mathbf{S O}_{4}\right]$ & 124 & 57 & 164 \\
\hline $\mathbf{6}$ & $\mathbf{P V D F} /[\mathbf{E m i m}][\mathbf{T F S I}]$ & 120 & 47 & 162 \\
\hline
\end{tabular}




\begin{tabular}{|c|c|c|c|c|}
\hline $\mathbf{7}$ & PVDF/[C4C1pyrr][TFSI] & 119 & 39 & 162 \\
\hline $\mathbf{8}$ & PVDF/[Hmim][TFSI] & 120 & 57 & 165 \\
\hline $\mathbf{9}$ & PVDF/[N1112OH][TFSI] & 119 & 62 & 158 \\
\hline $\mathbf{1 0}$ & PVDF/[P66614][TFSI] & 134 & 40 & 173 \\
\hline
\end{tabular}

PVDF presents a well-defined single endothermic peak associated with melting at 168 ${ }^{\circ} \mathrm{C}$ (Figure 5a), which matches with the melting of the $\alpha$-phase previously reported [2]. $T_{\mathrm{m}}$ is lowered upon the addition of [Emim][TFSI], [Emim][Cl], and [Emim][PF 6$]$ to a minimum of $158^{\circ} \mathrm{C}$. It should be taken into account that the melting temperature of both $\alpha$ and $\beta$ PVDF phases is reported to be found within the range of $167-172{ }^{\circ} \mathrm{C}$ [2]. Therefore, although samples containing ILs show a $T_{\mathrm{m}}$ below the $167-172{ }^{\circ} \mathrm{C}$ range, their crystal structure still corresponds to $\alpha$ or $\beta$ phase, as the lowering of the melting temperature is due to the freezing point depression and the presence of specific interactions between PVDF macromolecules and free IL chains as shown in many miscible amorphous-crystalline (PVDF-IL in this specific case) blends [36-38].
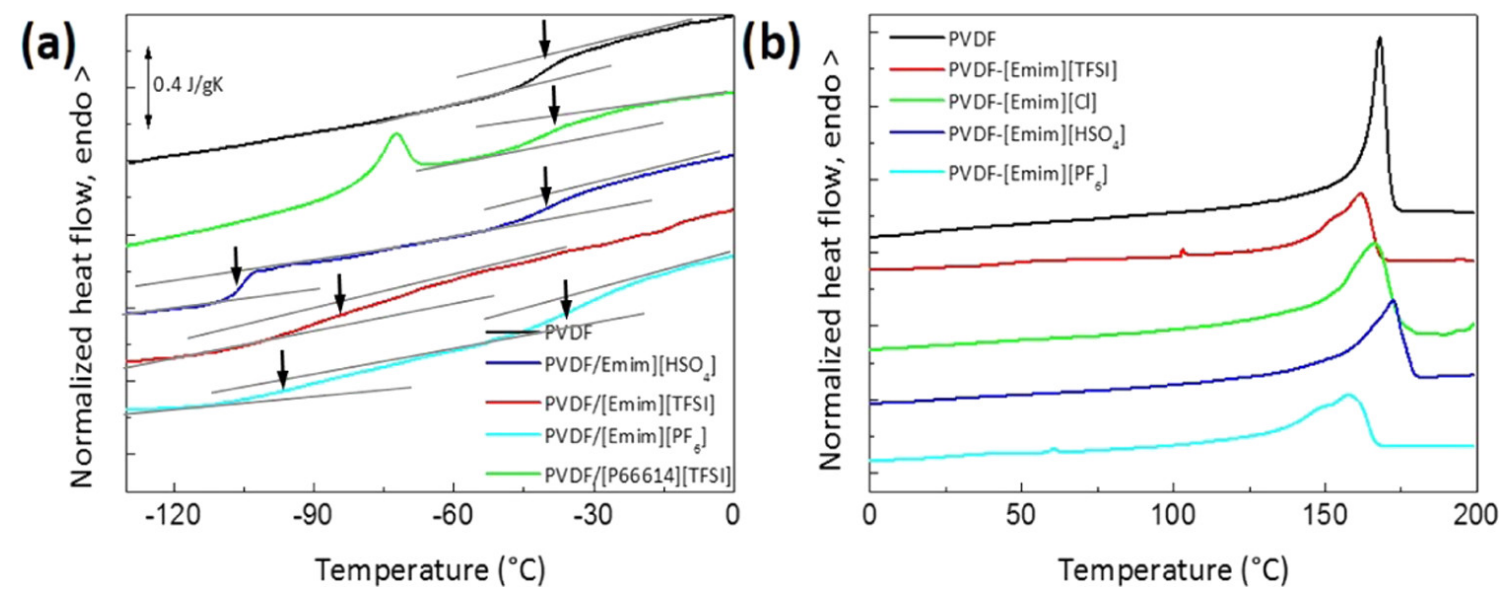

Fig. 5. DSC heating scans showing a) the glass transition and b) the melting of PVDF/IL blends. Normalized heat flow (heat flow divided by the sample mass and the heating rate) is represented.

The thermodynamic equilibrium criteria lead to the fact that when a solute is added to a liquid, its melting temperature decreases. This is known as the freezing point depression. Thus, if in the liquid mixture, above the melting temperature of PVDF, the ionic liquid dissolves homogeneously in the liquid PVDF, then the melting temperature of PVDF should decrease, as it is observed in the mixtures with [Emim][TFSI], [Emim][Cl], and $[$ Emim] $]\left[\mathrm{PF}_{6}\right]$. The inset in Figure $4 \mathrm{a}$ shows a schematic representation of the phase diagram of a blend that is miscible in the liquid phase but not in the solid phase. By 
cooling of a blend rich in PVDF, as it is the case of our blends, PVDF crystals form in equilibrium with a liquid blend, which becomes richer in the IL. This equilibrium takes place at a temperature lower than that of pure PVDF. Depression of both crystallization and melting temperatures (see Figure 5b) is a strong indication of the formation of PVDF crystals from a homogeneous liquid phase containing IL. Actually, in the case of polymeric systems, other kinetic factors must be considered. After IL incorporation, PVDF chains require longer migrating distances to reach the crystal growth front within the formed miscible blend, which in turn yields slower crystallization kinetics. As a consequence of such delayed crystallization ability, lower crystallization temperatures are obtained. Nevertheless, the relatively small IL content and the observed decrease of the melting temperature leads us to think that, in the present case, kinetic effects are less influential than thermodynamic ones.

If, on the contrary, the liquid PVDF and IL phases separate, the ionic liquid does not act as a solute of the PVDF and, therefore, the freeze-point depression does not occur and crystallization takes place in a pure PVDF phase. Furthermore, as the temperature of crystallization depends on the process of nucleation of the crystals and crystallization occurs more easily on surfaces already formed, such as impurities or interfaces, when phase separation occurs, the formed interfaces can act as nucleating agents and facilitate crystallization, leading to an increase of the crystallization temperature. The blends containing [Emim][HSO 4 ] (Figure 4a) and [P66614][TFSI] (figure 4b) show an increase of approximately $5{ }^{\circ} \mathrm{C}$ on their crystallization temperature, and the melting temperature $\left(T_{\mathrm{m}}\right)$ increases by $5{ }^{\circ} \mathrm{C}$ as well (Figure $5 \mathrm{~b}$ ). These results suggest that the liquid phase is immiscible and, in addition, an efficient nucleating effect from the ionic liquids as the crystallization is accelerated [39]. It is also observed in Table 3 that the crystallization enthalpy per gram of PVDF in the blend increases from $47 \mathrm{~J} \mathrm{~g}^{-1}$ up to a maximum of 86 $\mathrm{J} \mathrm{g}^{-1}$ for the blend containing [Emim] $\left[\mathrm{HSO}_{4}\right]$. This increase indicates that a notably larger fraction of PVDF is able to crystallize during the cooling process when such IL is added. The addition of other ILs does not have such a marked nucleating effect. Therefore, it can be concluded that the role of most of the ILs is to act as a directing agent toward the $\beta$ phase, while $[\mathrm{Emim}]\left[\mathrm{HSO}_{4}\right]$ also acts as an effective nucleating element to enhance the extent of the crystalline fraction (and not only its conformation).

As miscible blends display a single glass-transition $\left(T_{\mathrm{g}}\right)$ intermediate between those of pure blend constituents and noncompatible blends typically have a double $T_{\mathrm{g}}$ region, DSC 
emerges as one of the most useful methods to study the miscibility in polymer blends [40,41]. DSC heating scans displaying glass transition are shown in Figure 5a. It is observed that depending on the incorporated IL, a single or a double glass transition is observed (marked by the arrows in Figure 5a). For instance, the PVDF/[Emim] $\left[\mathrm{HSO}_{4}\right]$ blend presents a well-defined step in the heat capacity at $-98{ }^{\circ} \mathrm{C}$ and a broader transition in the temperature range of -50 to $-10{ }^{\circ} \mathrm{C}$. The first transition is ascribed to the glass transition of the [Emim] $\left[\mathrm{HSO}_{4}\right]$, while the second one corresponds to the glass transition of a blend phase rich in PVDF [42]. PVDF/[P66614][TFSI] blend also displays two separated glass-transition regions, indicating that the blend is not miscible, while $\mathrm{PVDF} /[\mathrm{Emim}]\left[\mathrm{PF}_{6}\right]$ shows indication of two broad glass transitions that are ascribed to the partial miscibility between the two components and no signs of IL melting is observed. On the contrary, PVDF/[Emim][TFSI] blend displays a single and broad transition, suggesting a good miscibility between the ILs and the amorphous regions of PVDF, as previously observed in FTIR results. The fact that the vitrification behaviors of the different blends are much different from each other indicates a very different interaction between the PVDF and the anion of the IL.

The heating scans of Figure 5 show melting peaks that are clearly widened toward the low-temperature side of the peak, as expected to occur in a mixture of the polymer with a low-molecular-weight substance [43]. However, except in the case of the PVDF mixture with [P66614][TFSI], the thermogram does not show a melting peak associated with the melting of IL crystals or the eutectic point. This melting peak in PVDF/[P66614][TFSI] appears at very low temperatures, around $-70{ }^{\circ} \mathrm{C}$. In all of the other blends, at temperatures below $0{ }^{\circ} \mathrm{C}$, the glass transition appears and the vitrification of the $\mathrm{IL}$ prevents the appearance of the eutectic point. The temperature of the endothermic peak corresponds thus to the melting of the PVDF crystals and are listed in Table 3.

Although DSC does not allow distinguishing between $\alpha$ and $\beta$ phases due to their very similar $T_{\mathrm{m}}\left(167-172{ }^{\circ} \mathrm{C}[2]\right)$, the degree of crystallinity $\left(X_{\mathrm{c}} \%\right)$ obtained during the cooling process can be extracted from the DSC melting enthalpy (Figure 5b) according to the following equation [2]:

$$
X_{c}(\%)=\frac{\Delta H_{S}}{\left(x \Delta H_{\alpha}+y \Delta H_{\beta}\right) \cdot W_{m}}
$$


where $\Delta H_{\mathrm{s}}$ is the melting enthalpy of the sample, $W_{\mathrm{m}}$ is the PVDF matrix weight fraction, and $\Delta H_{\alpha}$ and $\Delta H_{\beta}$ are the heats of fusion for $100 \%$ crystalline $\alpha$-PVDF and $\beta$-PVDF, respectively (set at 93.07 and $104.6 \mathrm{~J} \mathrm{~g}^{-1}$, respectively) [2].

When accounting for the $X_{\mathrm{c}}$ of PVDF/IL blends, one should be aware that the mixing enthalpy may also contribute to the measured enthalpy. In any case, since melting enthalpy is much larger than the mixing enthalpy between polymer and IL, in this work, $X_{\mathrm{c}}$ has been estimated according to Equation 2. Overall, in comparison to neat PVDF, blends show a slight $X_{\mathrm{c}}$ depression from 55 to nearly $45 \%$ as a result of the restriction suffered by PVDF macromolecules to organize themselves into ordered regions during the cooling from the melt, which also denotes a good miscibility between both blend constituents. [18].

\subsection{PVDF segmental relaxation}

FTIR and DSC results indicate that miscibility in PVDF/IL blends is quite dependent on the IL structure within the explored composition range. In this sense, dynamic mechanical analyses (DMA) have been carried out to investigate the effect of different IL on the chain segmental relaxation of PVDF. Figure 6 displays the obtained dynamic mechanical storage modulus $\left(E^{\prime}\right)$ and the mechanical damping factor ( $\tan \delta=E^{\prime \prime} / E^{\prime}$; also known as loss factor) for the processed PVDF/IL blends over the temperature range of -100 to $125^{\circ} \mathrm{C}$. It is observed in Figure 6a,c that in the glassy region, at temperatures below $-50{ }^{\circ} \mathrm{C}$, all of the blends present similar values of $E^{\prime}$. The exception is the blend [Emim] $\left[\mathrm{PF}_{6}\right]$ in which $E^{\prime}$ in the glassy state is around half of the other blends. In the main dynamic mechanical relaxation of the amorphous phase, $E^{\prime}$ drops up to a decade upon IL incorporation with respect to pure PVDF. In other words, neat PVDF can keep its structural integrity once the $T_{\mathrm{g}}$ has been overcome, suggesting an increased chain stiffness in comparison to IL-containing samples[44]. Similar behavior has also been observed for IL-blended zwitterionic copolymers, where the IL incorporation results in a reduced electrostatic interaction between ion pairs within the copolymers, increasing the chain mobility and therefore lowering the rubbery plateau [45]. 

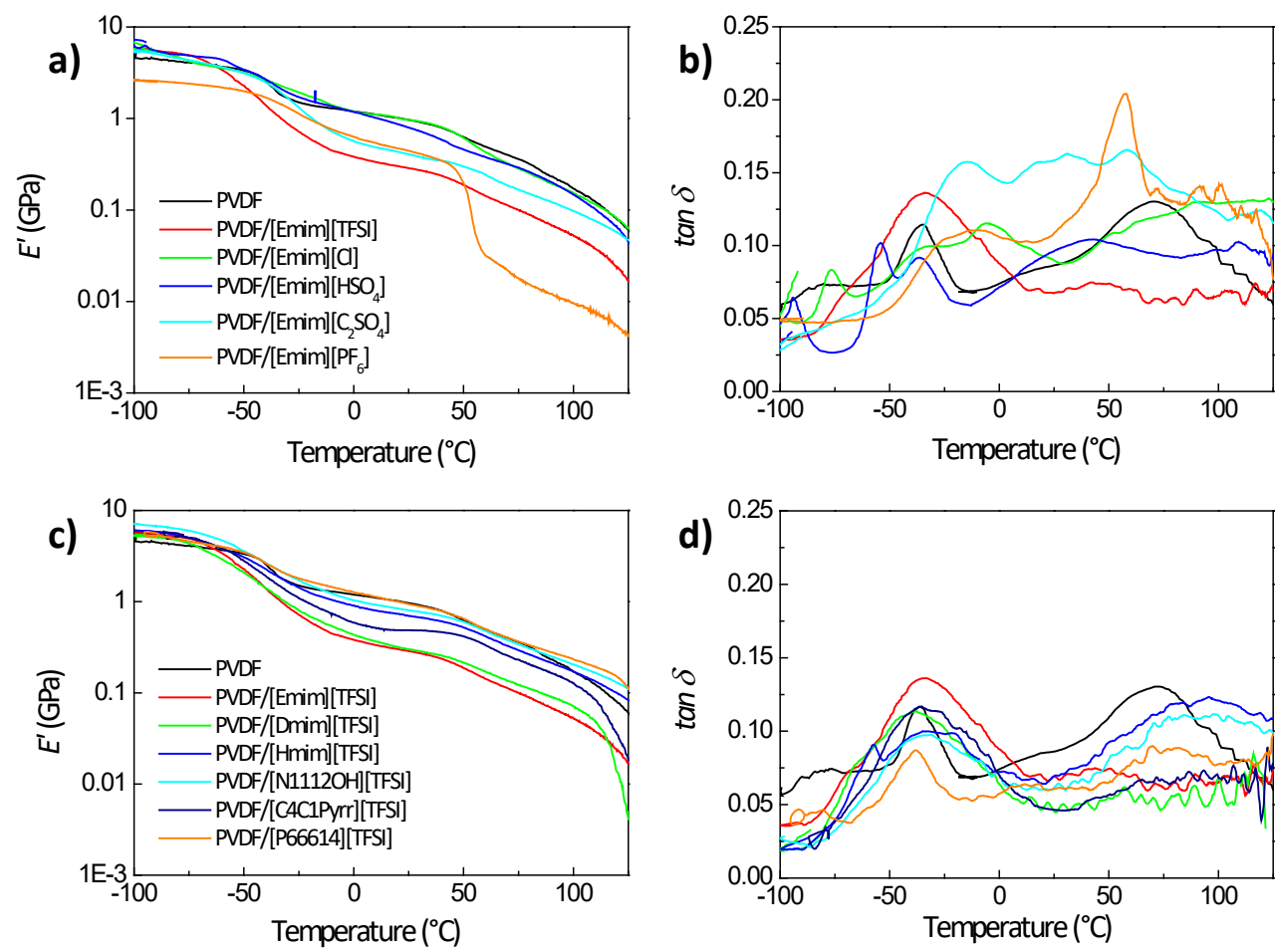

Fig. 6. Dynamic mechanical storage modulus vs. temperature (a and c) and the corresponding $\tan \delta$ vs. temperature (b and d) curves for PVDF/IL blends. The influence of the anion is highlighted in Fig. 5a and b, while Fig. 5c and d show blends having different cations.

As observed in Figure 6b, neat PVDF is characterized by two main relaxations centered at -35 and $73{ }^{\circ} \mathrm{C}$, attributed to the $\beta_{\mathrm{DMA}}$ relaxation arising from the cooperative segmental motions in the amorphous region and to the $\alpha_{\text {DMA }}$ relaxation of the imperfections present within the crystalline phases, respectively [46]. This second relaxation achieved at temperatures above $T_{\mathrm{g}}$ involves $180^{\circ}$ flip motions of the chain sections within the crystalline lamellae and has been also found in other semicrystalline polymers such as isotactic polypropylene, polyethylene, or poly(ethylene oxide) $[47,48]$. Additionally, the shoulder in the $\tan \delta$ signal corresponding to neat PVDF that can be observed in Figure $6 \mathrm{~b}$ at temperatures around $23{ }^{\circ} \mathrm{C}$ has been ascribed to the chain movements at the amorphous-crystal interface [49].

With respect to the amorphous region, there is a correlation between the presence of a single broad glass transition in the DSC thermograms and a broad $\tan \delta$ peak in the $\beta_{\mathrm{DMA}}$ of the samples, in which there is an homogeneous mixture of IL molecules and amorphous PVDF chains in the amorphous phase of the blend. Thus, Figure $6 \mathrm{~b}$ shows in this temperature range a single very wide $\tan \delta$ peak in the PVDF/[Emim][TFSI] mixture, 
which covers practically the entire interval between -80 and $+20^{\circ} \mathrm{C}$ (red arrow in Figure 6b), confirming the miscibility of this mixture. In the opposite case, the $\mathrm{PVDF} /[\mathrm{Emim}]\left[\mathrm{HSO}_{4}\right]$ mixture clearly shows a $\tan \delta$ peak close to $-100{ }^{\circ} \mathrm{C}$, which is associated with the glass transition of the IL, while between -60 and $-10{ }^{\circ} \mathrm{C}$, a complex relaxation process appears, which is associated with the glass transition of the phase of the mixture richest in PVDF chains (blue arrows in Figure 6b), correlating with the two clearly separated glass transitions observed in the DSC thermograms (Figure 5a).

Overall, the $\tan \delta$ value slightly increases for the blends, suggesting an increased presence of additional free volume upon blending with ILs. The rather marked decrease in $\mathrm{E}^{\prime}$ for the PVDF/[Emim][PF6] blend at around $53{ }^{\circ} \mathrm{C}$ is accompanied by a lowering in the relaxation temperatures corresponding to the chain movements at the amorphouscrystal interface (from 23 to $-10^{\circ} \mathrm{C}$ ) and within the crystalline phases (from 73 to $57^{\circ} \mathrm{C}$ ). This effect is ascribed to the plasticizing effect of [Emim][PF6], which, apart from introducing additional free volume within the blend, limits the intermolecular interactions between PVDF chains. As a result, lower energy (temperature) is required to reach a given relaxation. The plastizicing effect of the IL on the glass transition of PVDF supports the mixture of PVDF chain segments and IL molecules in the amorphous phase. Conversely, despite to the plasticizing effect of ILs, the other blends show increased transition temperatures compared to neat PVDF. This may be ascribed to the presence of a more packed chain structure, as the PVDF crystalline phase shifts from the $\alpha$ - to $\beta$-phase. Indeed, $\beta$-PVDF shows a more packed crystalline structure in regard to the $\alpha$-PVDF (with a density of 1.99 and $1.92 \mathrm{~g} \mathrm{~cm}-3$ for $\beta$ - and $\alpha$-phases, respectively) [50].

Since IL molecules cannot fit into the crystalline structure of the PVDF crystallites, when PVDF chains crystallize from the homogeneous liquid mixture with the lowmolecular-weight IL, IL molecules are displaced to the amorphous interlamellae and interspherulite spaces. In fact, the DMA data in the region of the $\beta_{\mathrm{DMA}}$ relaxation and the DSC data in the glass-transition region demonstrate that in some mixtures, an homogeneous blend with the polymer is formed, while in other mixtures, two separated amorphous phases coexist, as in the case of $\mathrm{PVDF} /[\mathrm{Emim}]\left[\mathrm{HSO}_{4}\right]$.

Overall, those results agree with FTIR and DSC findings, where a concomitant plasticizing and directing (toward the $\beta$-phase) effect of ionic liquids has been observed. 


\section{Conclusions}

Different ILs comprising different cations and anions were incorporated into the PVDF polymer matrix. Ten different ILs containing 1-ethyl-3-methylimidazolium [Emim] as a fixed cation (five of them) and ILs containing bis(trifluoromethylsulfonyl)imide [TFSI] as a fixed anion (another five) were incorporated into PVDF at a concentration of $25 \mathrm{wt}$ $\%$ through solvent casting followed by solvent evaporation at $210{ }^{\circ} \mathrm{C}$ in an air oven. The effect of IL on the conformational, thermal, and dynamic mechanical behaviors of PVDF was evaluated. It is shown that while most of the blends having [Emim] as a common cation crystallize in the electroactive $\beta$-PVDF phase, blends having [TFSI] as a common anion crystallize in a mixture of $\alpha, \beta$, and $\gamma$ phases.

As a general trend, IL incorporation delays the PVDF crystallization and decreases both the glass-transition and melting temperatures of neat PVDF. Conversely, $\left[\right.$ Emim] $\left[\mathrm{HSO}_{4}\right]$ and [P66614][TFSI] increase the crystallization and melting temperature of PVDF, suggesting a nucleating role of such ILs. Overall, a concomitant plasticizing and directing (toward the $\beta$-phase) effect of ionic liquids has been observed. Experimental findings here reported shed light on the relevance of properly selecting the optimum cation-anion balance to promote the formation of the electroactive and highly polar PVDF $\beta$-phase, which play a relevant role in applications such as sensors and actuators, biomedicine, and energy storage systems.

\section{Acknowledgements}

This work was supported by the Portuguese Foundation for Science and Technology (FCT) in the framework of the Strategic Funding UID/FIS/04650/2019. The authors thank FEDER funds through the COMPETE 2020 Programme and National Funds through FCT under the projects PTDC/BTM-MAT/28237/2017, PTDC/EEI-SII/5582/2014, and PTDC/FIS-MAC/28157/2017. D.M.C. and C.M.C. also acknowledge the FCT for grants SFRH/BPD/121526/2016 and SFRH/BPD/112547/2015, respectively. The financial supports from the Spanish Ministry of Economy and Competitiveness (MINECO) through the project MAT2016-76039-C4-(1 and 3)-R (AEI/FEDER, UE) (including the FEDER financial support) and from the Basque Government Industry and Education Departments under the ELKARTEK, HAZITEK, and PIBA (PIBA-2018-06) programs, respectively, are acknowledged. CIBER-BBN is an initiative funded by the VI National 
R\&D\&I Plan 2008-2011, Iniciativa Ingenio 2010, Consolider Program. CIBER Actions are financed by the Instituto de Salud Carlos III with assistance from the European Regional Development Fund. 


\section{References}

[1] C.M. Costa, M.M. Silva, S. Lanceros-Méndez, Battery separators based on vinylidene fluoride (VDF) polymers and copolymers for lithium ion battery applications, RSC Adv. 3 (2013) 11404-11417. https://doi.org/10.1039/c3ra40732b.

[2] P. Martins, A.C. Lopes, S. Lanceros-Mendez, Electroactive phases of poly(vinylidene fluoride): Determination, processing and applications, Prog. Polym. Sci. 39 (2014) 683-706. https://doi.org/10.1016/j.progpolymsci.2013.07.006.

[3] G. Kang, Y. Cao, Application and modification of poly(vinylidene fluoride) (PVDF) membranes - A review, J. Memb. Sci. 463 (2014) 145-165. https://doi.org/https://doi.org/10.1016/j.memsci.2014.03.055.

[4] H. Wei, J. Ma, B. Li, Y. Zuo, D. Xia, Enhanced Cycle Performance of LithiumSulfur Batteries Using a Separator Modified with a PVDF-C Layer, ACS Appl. Mater. Interfaces. 6 (2014) 20276-20281. https://doi.org/10.1021/am505807k.

[5] Y. Zhao, Q. Liao, G. Zhang, Z. Zhang, Q. Liang, X. Liao, Y. Zhang, High output piezoelectric nanocomposite generators composed of oriented $\mathrm{BaTiO} 3$ NPs@PVDF, Nano Energy. 11 (2015) 719-727. https://doi.org/https://doi.org/10.1016/j.nanoen.2014.11.061.

[6] Y. Ahn, J.Y. Lim, S.M. Hong, J. Lee, J. Ha, H.J. Choi, Y. Seo, Enhanced piezoelectric properties of electrospun poly(vinylidene fluoride)/multiwalled carbon nanotube composites due to high $\beta$-phase formation in poly(vinylidene fluoride), J. Phys. Chem. C. 117 (2013) 11791-11799. https://doi.org/10.1021/jp4011026.

[7] L.T. Vo, E.P. Giannelis, Compatibilizing Poly(vinylidene fluoride)/Nylon-6 Blends with Nanoclay, Macromolecules. 40 (2007) 8271-8276. https://doi.org/10.1021/ma071508q.

[8] H. Gunawan, A. Sugondo, C.-W. Chiu, A New Approach of Polyvinylidene Fluoride (PVDF) Poling Method for Higher Electric Response AU - Ting, Yung, Ferroelectrics. 446 (2013) 28-38.

https://doi.org/10.1080/00150193.2013.820983.

[9] V. Sencadas, R. Gregorio, S. Lanceros-Méndez, $\alpha$ to $\beta$ phase transformation and microestructural changes of PVDF films induced by uniaxial stretch, J. 
Macromol. Sci. Part B Phys. 48 (2009) 514-525.

https://doi.org/10.1080/00222340902837527.

[10] V. Cauda, S. Stassi, K. Bejtka, G. Canavese, Nanoconfinement: an Effective Way to Enhance PVDF Piezoelectric Properties, ACS Appl. Mater. Interfaces. 5 (2013) 6430-6437. https://doi.org/10.1021/am4016878.

[11] X. Zheng, Q. Lin, P. Jiang, Y. Li, J. Li, Ionic Liquids Incorporating Polyamide 6: Miscibility and Physical Properties, Polym. . 10 (2018).

https://doi.org/10.3390/polym10050562.

[12] M.P. Scott, M. Rahman, C.S. Brazel, Application of ionic liquids as lowvolatility plasticizers for PMMA, Eur. Polym. J. 39 (2003) 1947-1953. https://doi.org/https://doi.org/10.1016/S0014-3057(03)00129-0.

[13] M. Rahman, C.S. Brazel, Ionic liquids: New generation stable plasticizers for poly(vinyl chloride), Polym. Degrad. Stab. 91 (2006) 3371-3382. https://doi.org/https://doi.org/10.1016/j.polymdegradstab.2006.05.012.

[14] H. Weingärtner, Understanding Ionic Liquids at the Molecular Level: Facts, Problems, and Controversies, Angew. Chemie Int. Ed. 47 (2008) 654-670. https://doi.org/10.1002/anie.200604951.

[15] J.G. Huddleston, A.E. Visser, W.M. Reichert, H.D. Willauer, G.A. Broker, R.D. Rogers, Characterization and comparison of hydrophilic and hydrophobic room temperature ionic liquids incorporating the imidazolium cation, Green Chem. 3 (2001) 156-164. https://doi.org/10.1039/B103275P.

[16] L. He, J. Sun, X. Wang, C. Wang, R. Song, Y. Hao, Facile and effective promotion of $\beta$ crystalline phase in poly(vinylidene fluoride) via the incorporation of imidazolium ionic liquids, Polym. Int. 62 (2013) 638-646. https://doi.org/10.1002/pi.4339.

[17] A. Bahader, G. Haoguan, M. Nawaz, M. Bangesh, F. Bangesh, M. Ibrar, D. Yunsheng, Impact of ionic liquid's self-assembly on the crystallization behavior of poly (vinylidene fluoride), J. Mol. Liq. 276 (2019) 115-119. https://doi.org/https://doi.org/10.1016/j.molliq.2018.11.145.

[18] C. Xing, M. Zhao, L. Zhao, J. You, X. Cao, Y. Li, Ionic liquid modified poly(vinylidene fluoride): crystalline structures, miscibility, and physical properties, Polym. Chem. 4 (2013) 5726-5734. https://doi.org/10.1039/C3PY00466J.

[19] R. Mejri, J.C. Dias, A.C. Lopes, S. Bebes Hentati, M.M. Silva, G. Botelho, A. 
Mão de Ferro, J.M.S.S. Esperança, A. Maceiras, J.M. Laza, J.L. Vilas, L.M. León, S. Lanceros-Mendez, Effect of ionic liquid anion and cation on the physico-chemical properties of poly(vinylidene fluoride)/ionic liquid blends, Eur. Polym. J. 71 (2015) 304-313. https://doi.org/10.1016/j.eurpolymj.2015.07.058.

[20] D.M. Correia, R. Sabater i Serra, J.A. Gómez Tejedor, V. de Zea Bermudez, A. Andrio Balado, J.M. Meseguer-Dueñas, J.L. Gomez Ribelles, S. LancerosMéndez, C.M. Costa, Ionic and conformational mobility in poly(vinylidene fluoride)/ionic liquid blends: Dielectric and electrical conductivity behavior, Polym. (United Kingdom). 143 (2018). https://doi.org/10.1016/j.polymer.2018.04.019.

[21] J.C. Dias, D.M. Correia, C.M. Costa, C. Ribeiro, A. Maceiras, J.L. Vilas, G. Botelho, V. de Zea Bermudez, S. Lanceros-Mendez, Improved response of ionic liquid-based bending actuators by tailored interaction with the polar fluorinated polymer matrix, Electrochim. Acta. 296 (2019) 598-607. https://doi.org/10.1016/j.electacta.2018.11.049.

[22] J.C. Dias, M.S. Martins, S. Ribeiro, M.M. Silva, J.M.S.S. Esperança, C. Ribeiro, G. Botelho, C.M. Costa, S. Lanceros-Mendez, Electromechanical actuators based on poly(vinylidene fluoride) with [N1 $1112(\mathrm{OH})][\mathrm{NTf} 2]$ and [C2mim] [C2SO4], J. Mater. Sci. 51 (2016) 9490-9503. https://doi.org/10.1007/s10853-016-0193-0.

[23] C. Ribeiro, C.M. Costa, D.M. Correia, J. Nunes-Pereira, J. Oliveira, P. Martins, R. Gonçalves, V.F. Cardoso, S. Lanceros-Méndez, Electroactive poly(vinylidene fluoride)-based structures for advanced applications, Nat. Protoc. 13 (2018) 681704. https://doi.org/10.1038/nprot.2017.157.

[24] D.M. Correia, J.C. Barbosa, C.M. Costa, P.M. Reis, J.M.S.S. Esperança, V. de Zea Bermudez, S. Lanceros-Méndez, Ionic Liquid Cation Size-Dependent Electromechanical Response of Ionic Liquid/Poly(vinylidene fluoride)-Based Soft Actuators, J. Phys. Chem. C. (2019) acs.jpcc.9b00868. https://doi.org/10.1021/acs.jpcc.9b00868.

[25] V. Sencadas, R. Gregorio Filho, S. Lanceros-Mendez, Processing and characterization of a novel nonporous poly(vinilidene fluoride) films in the $\beta$ phase, J. Non. Cryst. Solids. 352 (2006) 2226-2229. https://doi.org/https://doi.org/10.1016/j.jnoncrysol.2006.02.052.

[26] X. Cai, T. Lei, D. Sun, L. Lin, A critical analysis of the $\alpha, \beta$ and $\gamma$ phases in poly(vinylidene fluoride) using FTIR, RSC Adv. 7 (2017) 15382-15389. 
https://doi.org/10.1039/C7RA01267E.

[27] B.S. Ince-Gunduz, R. Alpern, D. Amare, J. Crawford, B. Dolan, S. Jones, R. Kobylarz, M. Reveley, P. Cebe, Impact of nanosilicates on poly(vinylidene fluoride) crystal polymorphism: Part 1. Melt-crystallization at high supercooling, Polymer (Guildf). 51 (2010) 1485-1493.

https://doi.org/https://doi.org/10.1016/j.polymer.2010.01.011.

[28] A.C. Lopes, C.M. Costa, C.J. Tavares, I.C. Neves, S. Lanceros-Mendez, Nucleation of the Electroactive $\gamma$ Phase and Enhancement of the Optical Transparency in Low Filler Content Poly(vinylidene)/Clay Nanocomposites, J. Phys. Chem. C. 115 (2011) 18076-18082. https://doi.org/10.1021/jp204513w.

[29] R.J. Crawford, J.L. Throne, Rotational Molding Polymers, in: Rotational Molding Technol., William Andrew Publishing, Norwich, NY, 2002: pp. 19- 68.

[30] C. Xing, L. Zhao, J. You, W. Dong, X. Cao, Y. Li, Impact of Ionic LiquidModified Multiwalled Carbon Nanotubes on the Crystallization Behavior of Poly(vinylidene fluoride), J. Phys. Chem. B. 116 (2012) 8312-8320. https://doi.org/10.1021/jp304166t.

[31] Y. Zhu, C. Li, B. Na, R. Lv, B. Chen, J. Zhu, Polar phase formation and competition in the melt crystallization of poly (vinylidene fluoride) containing an ionic liquid, Mater. Chem. Phys. 144 (2014) 194-198. https://doi.org/https://doi.org/10.1016/j.matchemphys.2013.12.042.

[32] A. Salimi, A.A. Yousefi, Conformational changes and phase transformation mechanisms in PVDF solution-cast films, J. Polym. Sci. Part B Polym. Phys. 42 (2004) 3487-3495. https://doi.org/10.1002/polb.20223.

[33] P. Martins, C.M. Costa, M. Benelmekki, G. Botelho, S. Lanceros-Mendez, On the origin of the electroactive poly(vinylidene fluoride) $\beta$-phase nucleation by ferrite nanoparticles via surface electrostatic interactions, CrystEngComm. 14 (2012) 2807-2811. https://doi.org/10.1039/c2ce06654h.

[34] A. Salimi, A.A. Yousefi, Analysis Method: FTIR studies of $\beta$-phase crystal formation in stretched PVDF films, Polym. Test. 22 (2003) 699-704. https://doi.org/https://doi.org/10.1016/S0142-9418(03)00003-5.

[35] H. Zhang, W. Shi, H. Cheng, S. Chen, L. Wang, Effect of ionic liquid on crystallization kinetics and crystal form transition of poly(vinylidene fluoride) blends, J. Therm. Anal. Calorim. 132 (2018) 1153-1165. https://doi.org/10.1007/s10973-018-7029-X. 
[36] P.B. Rim, J.P. Runt, Melting point depression in crystalline/compatible polymer blends, Macromolecules. 17 (1984) 1520-1526. https://doi.org/10.1021/ma00138a017.

[37] P. Greco, E. Martuscelli, Crystallization and thermal behaviour of poly $(\mathrm{d}(-)-3-$ hydroxybutyrate)-based blends, Polymer (Guildf). 30 (1989) 1475-1483. https://doi.org/https://doi.org/10.1016/0032-3861(89)90219-X.

[38] M.M. Coleman, P.C. Painter, Hydrogen-Bonded Polymer Blends, Prog. Polym. Sci. 20 (1995) 1-59. https://doi.org/10.1016/0079-6700(94)00038-4.

[39] E. Lizundia, A. Oleaga, A. Salazar, J.R. Sarasua, Nano- and microstructural effects on thermal properties of poly (l-lactide)/multi-wall carbon nanotube composites, Polymer (Guildf). 53 (2012) 2412-2421. https://doi.org/10.1016/j.polymer.2012.03.046.

[40] X. Hao, J. Kaschta, X. Liu, Y. Pan, D.W. Schubert, Entanglement network formed in miscible PLA/PMMA blends and its role in rheological and thermomechanical properties of the blends, Polymer (Guildf). 80 (2015) 38-45. https://doi.org/https://doi.org/10.1016/j.polymer.2015.10.037.

[41] E. Lizundia, E. Meaurio, J.M. Laza, J.L. Vilas, L.M. León Isidro, Study of the chain microstructure effects on the resulting thermal properties of poly $(\mathrm{L}-$ lactide)/poly(N-isopropylacrylamide) biomedical materials, Mater. Sci. Eng. C. 50 (2015) 97-106. https://doi.org/10.1016/j.msec.2015.01.097.

[42] Y. Lin, L. Liu, G. Xu, D. Zhang, A. Guan, G. Wu, Interfacial Interactions and Segmental Dynamics of Poly(vinyl acetate)/Silica Nanocomposites, J. Phys. Chem. C. 119 (2015) 12956-12966. https://doi.org/10.1021/acs.jpcc.5b01240.

[43] G. Höhne, W.F. Hemminger, H.J. Flammersheim, Differential Scanning Calorimetry, Springer, Berlin, Heidelberg, 2013.

[44] E. Lizundia, S. Petisco, J.-R. Sarasua, Phase-structure and mechanical properties of isothermally melt-and cold-crystallized poly (L-lactide), J. Mech. Behav. Biomed. Mater. 17 (2012) 242-251. https://doi.org/10.1016/j.jmbbm.2012.09.006.

[45] R.H. Brown, A.J. Duncan, J.-H. Choi, J.K. Park, T. Wu, D.J. Leo, K.I. Winey, R.B. Moore, T.E. Long, Effect of Ionic Liquid on Mechanical Properties and Morphology of Zwitterionic Copolymer Membranes, Macromolecules. 43 (2010) 790-796. https://doi.org/10.1021/ma902028u.

[46] J. Mijovic, J.-W. Sy, T.K. Kwei, Reorientational Dynamics of Dipoles in 
Poly(vinylidene fluoride)/Poly(methyl methacrylate) (PVDF/PMMA) Blends by Dielectric Spectroscopy, Macromolecules. 30 (1997) 3042-3050. https://doi.org/10.1021/ma961774w.

[47] R.H. Boyd, Relaxation processes in crystalline polymers: molecular interpretation — a review, Polymer (Guildf). 26 (1985) 1123-1133. https://doi.org/https://doi.org/10.1016/0032-3861(85)90240-X.

[48] R.H. Boyd, Relaxation processes in crystalline polymers: experimental behaviour — a review, Polymer (Guildf). 26 (1985) 323-347. https://doi.org/https://doi.org/10.1016/0032-3861(85)90192-2.

[49] A. Mandal, A.K. Nandi, Physical properties of poly(vinylidene fluoride) composites with polymer functionalized multiwalled carbon nanotubes using nitrene chemistry, J. Mater. Chem. 21 (2011) 15752-15763. https://doi.org/10.1039/C1JM12926K.

[50] A. Mandal, A.K. Nandi, Ionic Liquid Integrated Multiwalled Carbon Nanotube in a Poly(vinylidene fluoride) Matrix: Formation of a Piezoelectric $\beta$-Polymorph with Significant Reinforcement and Conductivity Improvement, ACS Appl. Mater. Interfaces. 5 (2013) 747-760. https://doi.org/10.1021/am302275b. 


\section{Supporting Information}

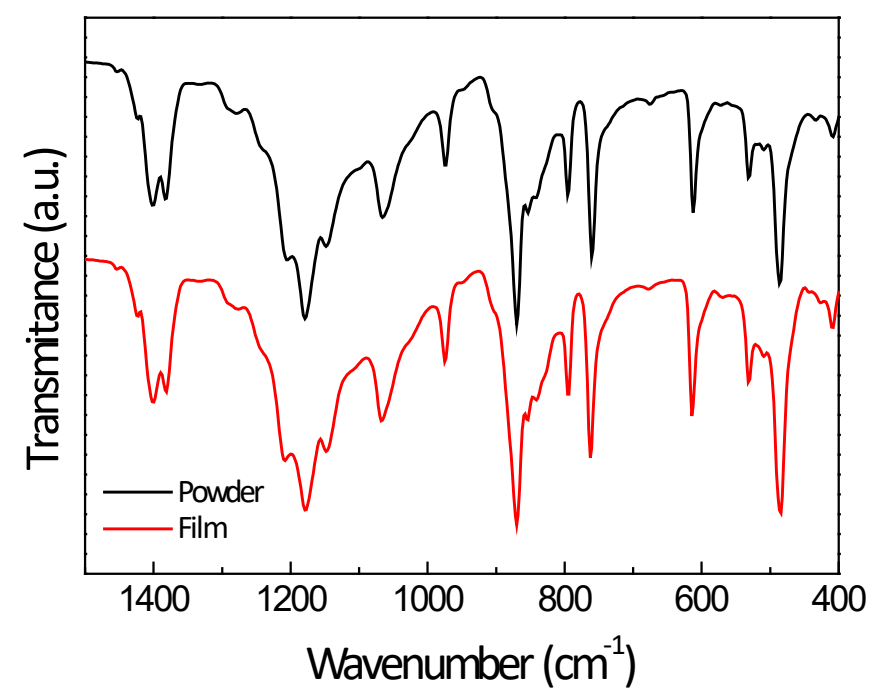

Fig. S1. FTIR spectra for the as-received PVDF powder and processed PVDF film after dissolving the powder in DMF and subsequent drying at $220{ }^{\circ} \mathrm{C}$ and cooling down to room temperature. 